\title{
Sepsis neonatal em díade mãe-fillho de minoria étnica: estudo de caso
}

\author{
Neonatal sepsis in mother-child dyad of ethnic minority: a case study \\ Sepsis neonatal en el binomio madre-hijo de minoría étnica: estudio de caso \\ Nikola Urbanovská (io https://orcid.org/0000-0003-3012-5069)! \\ Cristina Pedro (i) https://orcid.org/0000-0003-2587-1921) 2 \\ Maria Margarida Santana Fialho Sim-Sim io https://orcid.orgy/0000-0002-0028-2664)?
}

Como citar:

Urbanovská N, Pedro C, Sim-Sim MM. Sepsis neonatal em díade mãe-filho de minoria étnica: estudo de caso. Acta Paul Enferm. 2020;33:APE20180041

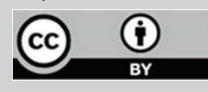

Descritores

oritários; Sepse neonatal; Recém-nascido

Keywords

Ethnic groups; Minority groups; Neonatal sepsis Infant, newborn

Descriptores

Grupos étnicos; Grupos minoritários; Sepsis neonatal; Recién nacido

Submetido 11 de Março de 2018

Aceito

15 de Agosto de 2019

Autor correspondente

Maria Margarida Santana Fialho Sim-Sim

E-mail:msimsim@uevora.pt

\section{Resumo}

Objetivo: Este trabalho objetivou descrever os diagnósticos e as intervenções de enfermagem na díade mãefilho coerentes com a situação sepsis neonatal aplicando-se a taxonomia NANDA-I.

Métodos: trata-se de uma pesquisa do tipo de estudo de caso, realizada com recém-nascido internado às $72 \mathrm{~h}$ de vida em serviço de neonatologia e com sua mãe que 0 acompanhou durante 0 internamento. Dados recolhidos em dezembro 2017. Os princípios éticos foram acautelados.

Resultados: A díade vive em condição social de minoria étnica, chamando a atenção para contextos sociais frágeis na área materno-infantil. Os dados sociodemográficos evidenciam precaridade na habitação, no planeamento da família, na vigilância pré-natal e nos papeis de género. A avaliação de enfermagem inicial concretizou-se em sete diagnósticos. Na criança: 1) padrão respiratório ineficaz (0032), 2) risco de glicémia instável (00179); 3) icterícia neonatal (00194); 4) risco de volume de líquidos deficiente (00028). Na mãe: 1) controle ineficaz da saúde (00078); 2) amamentação interrompida (00105); 3) disposição para tomada de decisão melhorada (00184). Definiram-se resultados esperados e intervenções de enfermagem que tiveram sucesso. A díade teve alta aos dez dias de internamento.

Conclusão: Programas de inclusão social e de assistência a minorias étnicas podem diminuir a morbilidade materno-infantil.

\section{Abstract}

Objective: This paper aimed to describe the nursing diagnoses and interventions in the mother-child dyad consistent with the neonatal sepsis situation by applying the NANDA-I taxonomy.

Methods: This is a case study research, conducted with a newborn hospitalized at 72 hours of life in a neonatology service and with his mother who followed him up during hospitalization. Data collected in December 2017. Ethical principles have been observed.

Results: The dyad lives in the social condition of an ethnic minority, drawing attention to fragile social contexts in the area of mother and child. Sociodemographic data show poor housing, family planning, prenatal surveillance and gender roles. The initial nursing assessment was based on seven diagnoses. In children: 1) ineffective breathing pattern (0032); 2) risk for unstable blood glucose level (00179); 3) neonatal jaundice (00194); 4) risk of poor fluid volume (00028). In mothers: 1) ineffective health control (00078); 2) interrupted breastfeeding (00105); 3) willingness for improved decision-making (00184). Expected outcomes and successful nursing interventions were defined. The dyad was discharged at ten days of hospitalization.

Conclusion: Social inclusion and ethnic minority care programs may decrease maternal and child morbidity. 


\section{Resumen}

Objetivo: Este trabajo tiene el objetivo de describir los diagnósticos y las intervenciones de enfermería en el binomio madre-hijo coherentes con la situación de sepsis neonatal, mediante la aplicación de la taxonomía NANDA-I.

Métodos: Se trata de una investigación de tipo estudio de caso, realizada con recién nacidos internados a las 72 horas de vida en el servicio de neonatología y con su madre que lo acompañó durante la internación. Datos recolectados en diciembre de 2017. Los principios éticos fueron garantizados.

Resultados: El binomio vive en condición social de minoría étnica y llama la atención en contextos sociales frágiles en el área materno-infantil. Los datos sociodemográficos muestran precariedad en la vivienda, en la planificación familiar, en el control prenatal y en los papeles de género. La evaluación de enfermería inicial se realizó en siete diagnósticos. En el niño: 1) patrón respiratorio ineficaz (0032), 2) riesgo de glucemia inestable (00179), 3) ictericia neonatal (00194), 4) riesgo de déficit de volumen de líquidos (00028). En la madre: 1) gestión ineficaz de la propia salud (00078), 2) interrupción de la lactancia materna (00105), 3) disposición para mejorar la toma de decisiones (00184). Se definieron resultados esperados e intervenciones de enfermería que tuvieron éxito. El binomio recibió el alta a los diez días de internación.

Conclusión: Programas de inclusión social y de asistencia a minorías étnicas pueden reducir la morbilidad materno-infantil.

\section{Introdução}

A sepsis neonatal, consiste numa infeção sistémica, que ocorre nos primeiros 28 dias de vida da criança. É causada por organismo patogénico (i.e., bactéria, vírus, fungo, parasita), que penetra por solução de continuidade da pele, por via respiratória, via conjuntival, gastrointestinal ou ainda através do coto umbilical. ${ }^{(1-3)}$

Embora o saneamento básico, o acesso a cuidados pré-natais ou o controlo de infeção hospitalar contribuam para a prevenção, morrem em cada ano cerca de 1 milhão de recém-nascidos $(\mathrm{RN})$ por sepsis. ${ }^{(4,5)} \mathrm{A}$ sepsis neonatal é mais frequente sob condições de higiene precária, pouca instruçáo materna e dadas estas caraterísticas, é mais expetável em populaçóes de fracos recursos económicos. A sepsis neonatal é denominada precoce (EOS=early-onset neonatal sepsis) quando o quadro se revela nas primeiras $72 \mathrm{~h}^{(1)}$ ou 7 dias de vida ${ }^{(2)}$ dominando fatores maternos. A forma de sepsis tardia (LOS=Late-onset neonatal sepsis) manifesta-se depois dos 7 dias de vida, dominando causas nosocomiais ou por contacto com a comunidade. ${ }^{(1,2)}$ Os fatores de risco para a EOS incluem rotura prematura de membranas (RPM) ou prolongada (i.e., além de $18 \mathrm{~h}$ ), parto prétermo, infeção materna e baixa condição socioeconómica. ${ }^{(2)}$ Em termos cronológicos a EOS é sobreponível ao pós-parto imediato, tal como o definem alguns autores, do $1^{\circ}$ ao $10^{\circ}$ dia. ${ }^{(3)}$ Nesta fase a vulnerabilidade materna é elevada, dadas as modificaçôes fisiológicas, a ansiedade ou os papeis maternais. ${ }^{(3,4)} \mathrm{O}$ quadro inicial de sepsis neonatal é frequentemente identificado pelo enfermeiro, assim como os problemas maternos subsequentes ao pós-parto.

No exercício clínico, os enfermeiros utilizam diversas classificaçóes diagnósticas como Nursing Minimum DataSet (NMDS), The Omaha System, a Classificação
Internacional para a Prática de Enfermagem (CIPE) ou ainda a taxonomia North American Nursing Diagnosis Association (NANDA-I). Em Portugal, dada a carência de publicaçôes, sobressai atualmente a necessidade de abordar a taxonomia NANDA-I. De facto, a formação em Enfermagem, ao abrir-se a espaços de mobilidade, tanto lusófonos como de outros contextos geográficos, depara não raras vezes com a necessidade de conhecimento nesta taxonomia.

De acordo com a NANDA-I, define-se o diagnóstico de enfermagem, através do julgamento clinico, sobre a resposta do individuo/família/comunidade, relativamente aos seus problemas de saúde, quer sejam reais ou potenciais, ou ainda referentes a processos de vida, que necessitam assistência de enfermagem. ${ }^{(6)}$ Os diagnósticos de Enfermagem pela NANDA-I contribuem para o julgamento clinico do enfermeiro. ${ }^{(3,5)}$ São coadjuvados pela Nursing Intervention Classification (NIC), que se refere ao tratamento oferecido, fundamentado no julgamento e conhecimento e pela Nursing Outcomes Classification (NOC), que se reporta a definição dos resultados a obter ${ }^{(6)}$ Os diagnósticos são possíveis de aplicar a todos os utentes, considerando mesmo a família ou relacionamentos de elevada interdependência, como é o caso da puérpera e recém-nascido $(\mathrm{RN})$. A taxonomia NANDA-I, é uma metodologia para tomadas de decisão, aplicável à situação da díade mãe-filho. Assim, utilizando a taxonomia NANDA-NIC-NOC, o objetivo do atual estudo de caso é descrever a avaliação inicial e a proposta de intervençóes de enfermagem a uma díade mãe-filho, que pertencendo a minoria étnica, enfrenta em meio hospitalar e no pós-parto a situação EOS.

\section{Descrição do caso clinico}

Estudo descritivo, qualitativo, realizado de acordo com modelo de autor para caso clinico ou caso in- 
formal. ${ }^{(7)}$ Partiu-se dos três passos iniciais reportados à 1) questão norteadora (i.e., qual é o problema), 2) identificação (i.e., recolha de dados/entrevista/ observação) e 3) problemas ou alteraçóes identificadas (i.e., categorização dos dados para levantamento dos diagnósticos). Seguidamente de forma simultânea, o atual estudo de caso 4) fundamenta teoricamente a fisiopatologia e contexto vivencial da díade, 5) procura na literatura resoluçôes, 6) descreve as resoluções. A sétima e última fase do modelo de autores, ${ }^{(7)}$ é no atual estudo de caso a discussão, procurando despertar o interesse dos profissionais e incentivando o raciocínio clínico.

$\mathrm{O}$ atual estudo resulta da assistência direta de enfermagem, em ambiente académico de aprendizagem, para conhecimento aprofundado das necessidades, problemas e condiçôes de saúde/doença da díade, no sentido de desvendar estratégias para os problemas. Estudo desenvolvido em hospital do Sul de Portugal. A unidade hospitalar é no sistema de saúde português um hospital central, que oferece cuidados intensivos neonatais na regiáo. $\mathrm{O}$ caso interessou aos atuais autores, dada a condição socioétnica da díade e o desconhecimento que emergia, na figura materna, relativamente aos papeis cuidativos e ao próprio enquadramento no sistema de saúde. Os dados foram recolhidos por observação direta no RN e por entrevista com a figura materna. No processo para a elaboração dos diagnósticos discutiu-se o quadro entre as duas enfermeiras clínicas e a orientadora pedagógica. Realizou-se a leitura da definição, as respetivas características definidoras, assim como os fatores relacionados. Utilizou-se a taxonomia NANDA-I, após a recolha de dados e respetivo julgamento clínico, traçando-se as intervençôes (NIC) e resultados esperados (NOC).Quanto aos aspetos ético-legais, utilizou-se o estratagema de nomes fictícios, para proteger a identidade da díade e assegurar a confidencialidade, como recomenda o artigo $106^{\circ}$ do Código Deontológico (i.e., Estatuto da Ordem dos Enfermeiros; Lei 156/2015 de 16 de setembro). O $\mathrm{RN}$ do sexo feminino toma designação de Bebé-Ana, a sua mãe é chamada de Maria. Solicitou-se o consentimento às figuras parentais do RN. Tal obteve-se após detalhada explicação sobre a finalidade do estudo, mas apenas no formato verbal, já que ambos os progenitores eram analfabetos.

\section{Resultados}

Antecedentes sociofamiliares da díade: $O$ BebéAna é filho de Maria de 17 anos, de etnia cigana que vive num clá seminómada percorrendo o Sul de Portugal. Sazonalmente, no inverno, o clã sedentariza-se, próximo de um agregado urbano, em habitação improvisada (i.e., barraca). A barraca, não tem saneamento básico, nem eletricidade. A água é pedida porta-a-porta no bairro próximo e conseguida de acordo com a boa/má-vontade dos vizinhos residentes.

Dados obstétricos da mãe: $\mathrm{O}$ índice obstétrico de Maria é $(2 ; 0 ; 0 ; 2)$. Primeiro filho nascido por cesariana quando Maria tinha 14 anos e o companheiro 17 anos. Durante a última gravidez, Maria foi duas vezes a consulta pré-natal e nas suas palavras, a gravidez decorreu bem. As análises de sangue, tinham nas suas palavras, resultados normais. Nega recolha de espécimes que possam ser interpretados como exsudado vaginal e anal para identificação de Streptococcus B entre a 35 e a 37 semana de gestação (i.e., Direção Geral de Saúde; Programa de vigilância de gravidez de baixo risco, 2015). Maria entrou no hospital com contraçóes dolorosas e bolsa amniótica rota. As suas declaraçóes sobre há quanto tempo a bolsa estava rota não foram concretas e coincidentes em momentos diferentes da recolha de dados, embora na última referência apontasse para duas horas antes de recorrer ao hospital. No exame de admissão apresentou líquido amniótico claro. Trabalho de parto que redundou em cesariana por não progressão.

Dados do recém-nascido: Após uma gestação de 40S+3d, o bebé-Ana nasceu por parto cesáreo. Apresentou APGAR 9-10-10. Pesou 4260 gr (i.e., percentil 97-99), media $52 \mathrm{~cm}$ (i.e., percentil 9597 e perímetro cefálico $36 \mathrm{~cm}$ (i.e., percentil 90). Foi-lhe administrado um biberão de leite artificial enquanto Maria estava no recobro cirúrgico. $\mathrm{Na}$ maioria dos episódios de alimentação seguintes fez aleitamento misto, a pedido da mãe, por considerar que o $\mathrm{RN}$ a) não pegava bem na mama e b) não tinha leite suficiente (i.e., mãe não estimulava a criança a mamar). Próximo da hora de alta hospitalar (i.e., cerca de $72 \mathrm{~h}$ de vida), a enfermeira do serviço de Obstetrícia chamou o pediatra constatando um 
quadro de: a) recém-nascido que não parece bem, b) apático, c) reperfusão capilar superior a 2 segundos com pele pletórica e d) momentos alternados de taquipneia versus bradipneia. O bebé-Ana foi transferido para a unidade de Neonatologia.

\section{Condução do caso clínico do bebé-Ana: $\mathrm{O}$} RN deu entrada na unidade de Neonatologia, às 72 horas de vida. Estava calmo e sem chorar. O bebé-Ana pesava $4220 \mathrm{gr}$ (i.e., perda de $40 \mathrm{gr}$ ), temperatura $36.8^{\circ} \mathrm{C}$, pulso $90 / \mathrm{m}$, ciclos respiratórios $36 / \mathrm{m}$. Exibia episódios de gemido expiratório, de adejo nasal e ainda de acrocianose peribucal quando era alimentado. Micção e dejeção presente na fralda de caraterísticas normais. Foi colocada em berçoninho nos cuidados intermédios. Iniciou antibio- terapia via EV de 12/12h e perOs/diária. Regime alimentar misto, com aleitamento materno quando visitada pela mãe e formula 3/3h (i.e., $50 \mathrm{ml}$ ). Mãe mostra-se preocupada e solicita explicaçôes detalhadas. As análises clínicas, revelaram Polymerase chain reaction (PCR) positiva. Análises de sangue e urina identificaram leucocitose. Foi diagnosticado sepsis neonatal, supondo-se transmissão vertical.

O método de trabalho na unidade de Neonatologia supõe a integração da família nos cuidados, facto pelo qual os diagnósticos dirigiram-se à díade mãe-filho. A avaliação do caso clinico foi realizada percorrendo os vários domínios da NANDA-I ${ }^{(8)}$ concretizando-se em sete diagnóstico. Considere-se a criança no quadro 1 e a progenitora no quadro 2 .

Quadro 1. Plano de cuidados ao recém-nascido à data da admissão na unidade de Neonatologia baseado na taxonomia NANDA-NIC-NOC

\begin{tabular}{|c|c|c|c|c|c|}
\hline Domínio & \multicolumn{3}{|l|}{ Diagnóstico de Enfermagem } & Objetivos NOC & Intervenções - NIC \\
\hline \multirow{4}{*}{ 崖员。 } & \multicolumn{3}{|l|}{ Recém-nascido } & & \\
\hline & \multirow{3}{*}{$\begin{array}{l}\text { 00032. Padrão respiratório ineficaz. } \\
\text { Inspiração e/ou expiração que não } \\
\text { proporciona ventilação adequada }\end{array}$} & \multirow{2}{*}{$\begin{array}{l}\text { Caraterísticas } \\
\text { definidoras: }\end{array}$} & Bradipneia/ Taquipneia & \multirow{3}{*}{$\begin{array}{l}0415 \text { Estado } \\
\text { respiratório }\end{array}$} & \multirow{3}{*}{$\begin{array}{l}\text { 6890. Monitorização do RN: frequência; simetria respiratória } \\
\text { sinais de angústia; ruídos; retração costal; cor da pele; } \\
\text { 3320: Oxigenoterapia (se agudização): preparar equipamente } \\
\text { de } 02 \text { humidificado para manter saturação } \geq 90 \%\end{array}$} \\
\hline & & & Padrão respiratório anormal & & \\
\hline & & Fatores relacionados: & Imaturidade neurológica & & \\
\hline \multirow{3}{*}{ 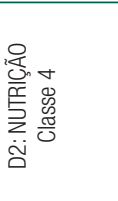 } & \multirow{3}{*}{$\begin{array}{l}\text { 00179: Risco de glicémia instável: } \\
\text { vulnerabilidade à variação dos níveis de } \\
\text { glicose/açúcar no sangue em relação à } \\
\text { variação normal, que pode comprometer } \\
\text { a saúde }\end{array}$} & \multirow[t]{3}{*}{ Fatores de risco } & $\begin{array}{l}\text { Condição de saúde física } \\
\text { comprometida }\end{array}$ & \multirow[t]{3}{*}{$\begin{array}{l}2300 \text { Nível de } \\
\text { glicemia }\end{array}$} & \multirow{3}{*}{$\begin{array}{l}\text { 2130. Gestão da hipoglicemia: manter via endovenosa } \\
\text { permeável; vigiar os níveis de glicose sanguínea; determinar } \\
\text { sinais e sintomas de hipoglicemia }\end{array}$} \\
\hline & & & $\begin{array}{l}\text { Ingestão alimentar } \\
\text { insuficiente }\end{array}$ & & \\
\hline & & & $\begin{array}{l}\text { Período de rápido } \\
\text { crescimento }\end{array}$ & & \\
\hline \multirow{5}{*}{ 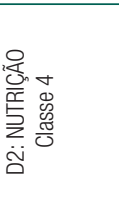 } & \multirow{5}{*}{$\begin{array}{l}\text { 00194. Icterícia neonatal: Coloração } \\
\text { amarelo-laranja da pele e mucosas do } \\
\text { neonato que ocorre após 24h de vida como } \\
\text { resultado da bilirrubina não conjugada na } \\
\text { circulação }\end{array}$} & \multirow{3}{*}{$\begin{array}{l}\text { Caraterísticas } \\
\text { definidoras: }\end{array}$} & Esclerótica amarelada & \multirow{5}{*}{$\begin{array}{l}\text { 0118. Adaptação } \\
\text { do RN }\end{array}$} & \multirow{5}{*}{$\begin{array}{l}\text { 6924. Fototerapia: explicar aos pais os procedimentos; } \\
\text { proteção ocular; colocar luz a 30cm; vigiar edema ocular; } \\
\text { mudar a posição }\end{array}$} \\
\hline & & & Pele amarelo-alaranjado & & \\
\hline & & & $\begin{array}{l}\text { Perfil sanguíneo } \\
\text { hemoconcentração }\end{array}$ & & \\
\hline & & \multirow{2}{*}{$\begin{array}{l}\text { Fatores } \\
\text { relacionados: }\end{array}$} & Idade $\leq 7$ dias & & \\
\hline & & & Padrão alimentar deficiente & & \\
\hline \multirow{3}{*}{ 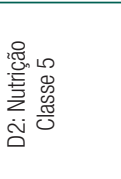 } & \multirow{3}{*}{$\begin{array}{l}\text { 00028. Risco de volume de líquidos } \\
\text { deficiente: Vulnerabilidade à diminuição } \\
\text { do líquido intravascular, intersticial e/ou } \\
\text { intracelular que pode comprometer a saúde }\end{array}$} & \multirow[t]{3}{*}{ Fatores de risco: } & Extremos de idade & \multirow{3}{*}{$\begin{array}{l}\text { 1608: controlo dos } \\
\text { sintomas } \\
\text { 1902: controlo do } \\
\text { risco }\end{array}$} & \multirow{3}{*}{$\begin{array}{l}\text { 4120. Gestão de líquidos: peso diário e controlo da evolução; } \\
\text { contar fraldas e pesar; registo preciso de ingesta e eliminação; } \\
\text { Vigiar estado de hidratação (mucosas, pulso, tensão arterial); } \\
\text { administrar terapêutica endovenosa; controlar resultados } \\
\text { laboratoriais; monitorizar estado nutricional; distribuir a ingesta } \\
\text { nas 24h; animar a mãe a amamentar }\end{array}$} \\
\hline & & & & & \\
\hline & & & $\begin{array}{l}\text { Mecanismo regulador } \\
\text { comprometido }\end{array}$ & & \\
\hline
\end{tabular}

Quadro 2. Plano de cuidados à mãe à data de admissão na unidade de Neonatologia baseado na taxonomia NANDA-NIC-NOC

\begin{tabular}{|c|c|c|c|c|c|}
\hline \multirow[t]{2}{*}{ Dominio } & \multicolumn{3}{|l|}{ Diagnóstico de Enfermagem } & Objetivos NOC & Intervenções - NIC \\
\hline & \multicolumn{3}{|l|}{ Mãe } & & \\
\hline \multirow{6}{*}{ 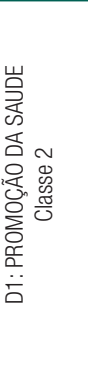 } & \multirow{6}{*}{$\begin{array}{l}\text { 00078. Controle ineficaz da saúde: } \\
\text { padrão de regulação e integração à vida } \\
\text { diária de um regime terapêutico para } \\
\text { tratamento de doenças e suas sequelas } \\
\text { que é insatisfatório para alcançar metas } \\
\text { especificas de saúde }\end{array}$} & \multirow{2}{*}{$\begin{array}{l}\text { Caraterísticas } \\
\text { definidoras }\end{array}$} & $\begin{array}{l}\text { Escolhas na vida diária } \\
\text { ineficazes para atingir as } \\
\text { metas de saúde }\end{array}$ & \multirow[t]{6}{*}{$\begin{array}{l}\text { 1803: comportamento } \\
\text { de cumprimento }\end{array}$} & \multirow{6}{*}{$\begin{array}{l}4360 \text { modificação do comportamento: fomentar hábitos } \\
\text { desejáveis; reforçar as decisões construtivas quanto às } \\
\text { necessidades sanitárias; facilitar a implicação de outros } \\
\text { cuidadores sanitários no processo de modificação } \\
5240 \text { Assessoramento: estabelecer relação terapêutica } \\
\text { baseada na confiança e respeito; estabelecer metas; } \\
\text { favorecer expressão de sentimentos; ajudar a identificar } \\
\text { pontos fortes e reforçar }\end{array}$} \\
\hline & & & $\begin{array}{l}\text { Falha em agir para reduzir } \\
\text { fatores de risco } \\
\end{array}$ & & \\
\hline & & \multirow{4}{*}{$\begin{array}{l}\text { Fatores } \\
\text { relacionados }\end{array}$} & Apoio social insuficiente & & \\
\hline & & & $\begin{array}{l}\text { Complexidade do sistema } \\
\text { de saúde }\end{array}$ & & \\
\hline & & & Desvantagem económica & & \\
\hline & & & $\begin{array}{l}\text { Padrão familiar de cuidados } \\
\text { de saúde }\end{array}$ & & \\
\hline
\end{tabular}


Continuação.

\begin{tabular}{|c|c|c|c|c|c|}
\hline Domínio & \multicolumn{3}{|l|}{ Diagnóstico de Enfermagem } & Objetivos NOC & Intervenções - NIC \\
\hline & \multicolumn{3}{|l|}{ Mãe } & & \\
\hline \multirow{5}{*}{ 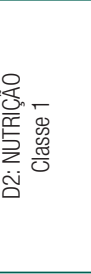 } & \multirow{5}{*}{$\begin{array}{l}\text { 00105. Amamentação interrompida. } \\
\text { Quebra na continuidade do oferecimento } \\
\text { de leite a um lactente ou criança pequena, } \\
\text { diretamente das mamas, que pode } \\
\text { comprometer o sucesso da amamentação } \\
\text { e/ou estado nutricional do lactente/criança }\end{array}$} & \multirow{2}{*}{$\begin{array}{l}\text { Caraterísticas } \\
\text { definidoras }\end{array}$} & $\begin{array}{l}\text { Amamentação não } \\
\text { exclusiva }\end{array}$ & \multirow[t]{5}{*}{$\begin{array}{l}\text { 1001: estabelecimento } \\
\text { da lactação materna }\end{array}$} & \multirow[t]{5}{*}{ 1054. Ajuda na lactação; ensinar métodos de extração } \\
\hline & & & Doença do lactente & & \\
\hline & & \multirow{3}{*}{$\begin{array}{l}\text { Fatores } \\
\text { relacionados }\end{array}$} & Hospitalização da criança & & \\
\hline & & & Separação mãe-lactente & & \\
\hline & & & $\begin{array}{l}\text { Falta de conhecimentos } \\
\text { para armazenar o leite } \\
\text { materno }\end{array}$ & & \\
\hline \multirow{3}{*}{ 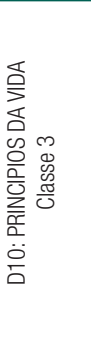 } & \multirow{3}{*}{$\begin{array}{l}\text { 00184. Disposição para tomada de decisão } \\
\text { melhorada: padrão de escolha de um curso } \\
\text { de ação suficiente para atingir metas de } \\
\text { saúde de curto e longo prazos e que pode } \\
\text { ser fortalecido }\end{array}$} & \multirow{3}{*}{$\begin{array}{l}\text { Caraterísticas } \\
\text { definidoras }\end{array}$} & $\begin{array}{l}\text { Expressa desejo de } \\
\text { aumentar a análise de } \\
\text { riscos/benefícios das } \\
\text { decisões }\end{array}$ & \multirow[t]{3}{*}{ 200014: Dignidade } & \multirow[t]{3}{*}{$\begin{array}{l}\text { 5270. Proporcionar segurança, aceitação e ânimo nos } \\
\text { momentos de tensão } \\
\text { 5250. Proporcionar informação e apoio para tomar decisão } \\
\text { sobre cuidados sanitários } \\
\text { 5390. Potencializar a consciência de si mesmo }\end{array}$} \\
\hline & & & $\begin{array}{l}\text { Expressa desejo de } \\
\text { aumentar a coerência } \\
\text { das decisões com valores } \\
\text { socioculturais }\end{array}$ & & \\
\hline & & & $\begin{array}{l}\text { Expressa desejo de } \\
\text { fortalecer a tomada de } \\
\text { decisão }\end{array}$ & & \\
\hline
\end{tabular}

\section{Discussão}

Os sinais clínicos de EOS do bebé-Ana são concordantes com a literatura, já que apesar de ocorrer uma síndrome inflamatória sistémica, consequência da invasão e multiplicação das bactérias na corrente sanguínea da criança, o quadro inicial é inespecífico. No caso do bebé-Ana, os dados analíticos de PCR positiva e leucocitose contribuíram para a suspensão da alta e internamento em Neonatologia. De facto, a variedade de sintomas dificulta a identificaçáo dos casos e como os testes diagnóstico têm pouca capacidade preditiva, é a clínica que na interpretação do seu global, leva à assunção da patologia. Discutem-se seguidamente os diagnósticos NANDA-I, formulados na fase de admissão ao serviço de Neonatologia.

\section{Discussão sobre os diagnósticos NANDA-I relativos ao bebé-Ana}

Padrão respiratório ineficaz (i.e., 0032): O bebé-Ana manifestou alternância bradipneia/taquipneia e padrão respiratório anormal. A dificuldade respiratória é a manifestaçăo mais comum na sepsis do $\mathrm{RN},{ }^{(9,10)}$ mas o diagnóstico 0032, nem sempre é fácil de estabelecer. É necessário distinguir entre a adaptação à mudança da respiraçáo tecidular em meio uterino versus respiração na atmosfera. Os fenómenos de encerramento do forâmen oval e canal arterial nos primeiros dias, mas também o nascimento por cesariana, poderiam mascarar a sintomatologia de sepsis.
De facto, a frequência respiratória com amplitude fisiológica de $30-60 / \mathrm{m}$ pode trazer dificuldades na caraterização. Por outro lado, não tendo ocorrido o confinamento ao canal de parto, é comum a retenção de fluido pulmonar e assim a taquipneia transitória do RN. Alem disso, a pletora neonatal é sintoma frequentemente associado a taquipenia transitória. $\mathrm{O}$ raciocínio clinico concluiu pelo registo de um padrão respiratório ineficaz, cuja taquipneia sem esforço respiratório (i.e., taquipneia silenciosa), está frequentemente associada à sepsis. ${ }^{(9,11)}$

Risco de glicémia instável (i.e., 00179): a glicemia fetal é alimentada por um fluxo permanente da progenitora, interrompendo-se com o nascimento. A macrossomia ao nascer do bebé-Ana terá resultado de hiperglicemia fetal. Nos bebés macrossómicos está aumentada a tendência para hipoglicemia. A instabilidade da glicémia é a situação que ocorre com maior frequência na fase neonatal, definindose como níveis plasmáticos de glicose $\leq 30 \mathrm{mg} / \mathrm{dl}$ nas primeiras $24 \mathrm{~h}$ ou $\leq 45 \mathrm{mg} / \mathrm{dl}$ nos dias seguintes. Para outros autores, a hipoglicemia é definida com valores $<40 \mathrm{mg} / \mathrm{dl}$, tanto nos $\mathrm{RN}$ a termo como nos prematuros. ${ }^{(9)}$ É importante considerar este risco, já que as sequelas próximas (i.e., convulsóes) ou a longo prazo (i.e., lesão neurológica; atraso cognitivo) têm forte impacto na vida atual e futura da criança.

Icterícia neonatal (i.e., 00194): a icterícia neonatal é a maioria das vezes um quadro fisiológico presente em 40 a 60\% dos RN. Dada a lise de eri- 
trócitos, libertam-se moléculas heme que se convertem em bilirrubina. Quando os níveis de bilirrubina excedem $7-8 \mathrm{mg} / \mathrm{dl}$, torna-se visível, manifestando-se na pele pletórica e conjuntivas amareladas. Contudo as infeçóes bacterianas levam a icterícia e assim na clinica, há que distinguir entre o quadro típico de hemólise versus o agravamento ou prolongamento da icterícia por sepsis. ${ }^{(9,10)}$

Dado que a criança fez aleitamento misto e a manifestação de icterícia ocorreu antes do final da primeira semana, exclui-se a possibilidade de icterícia por leite materno. A icterícia por leite materno ocorre em $2-4 \%$ de $\mathrm{RN}$ a termo, evidenciando aumento de bilirrubina náo conjugada. $\mathrm{O}$ leite destas mães inibe a enzima gluconiltranferase (i.e., enzima que conjuga a bilirrubina) e possui um metabolito esteroide (i.e., 20-betadiol) que altera a eliminação da bilirrubina. ${ }^{(9)}$

$\underline{\text { Risco de volume de líquidos deficiente (i.e., }}$ 00028): No choque distributivo ou choque séptico ocorre vasodilatação com consequente quadro de hipovolémia. As toxinas produzidas pelo microrganismo invasor, levam a libertação de oxido nítrico (i.e. produzindo vasodilatação) e citocinas, levando a desequilíbrios metabólicos. ${ }^{(10)} \mathrm{O}$ prejuízo tecidular causado pelo microrganismo invasor e as respostas pro-inflamatórias, influenciam a sintomatologia da sepsis. Se o dano tecidular é grande, a perfusão tecidual torna-se ineficaz. A resposta inflamatória sistémica agudiza-se e os órgãos vitais entram em risco de colapso. O quadro é mais frequente no $\mathrm{RN}$ cuja mãe tem um histórico de infeção periparto ou rotura prolongada de membranas. ${ }^{(9,10)}$

\section{Discussão sobre os diagnósticos NANDA-I relativos à mãe-Maria}

Controle ineficaz da saúde (00078): A identificação da EOS, fundamenta-se por vezes na retrospetiva da história obstétrica da mãe. No caso atual, a idade da mãe pode ter constituído um risco acrescido, já que tinha menos de 20 anos e o bebé-Ana é o segundo filho. Desconhece-se se houve infeção, quando Maria tinha 14 anos e nasceu o $1^{\circ}$ filho. Contudo os autores referem maior predisposição nas mulheres com infeção anterior e também nas mulheres abaixo dos 20 anos, dada a maior colonização vaginal com groupo B streptococcus (GBS). ${ }^{(2,10)}$ Maria teria assim fatores de risco que se tornam cumulativos. (12) Além destes aspetos, a não progressão do trabalho de parto levou a cesariana, outro fator predisponente para sepsis neonatal. (2) Com parto cesáreo, a possibilidade de contagio por passagem no canal vaginal diminui. Contudo a contaminação ascendente do liquido amniótico é possível, tanto com membranas intactas, como por rotura de membranas. ${ }^{(2,12)}$ Embora a franca rotura de membranas tivesse ocorrido $2 \mathrm{~h}$ antes do nascimento e assim longe do limite padronizado (i.e., >18h) desconhece-se se existiam micro roturas das membranas amnióticas, facilitando a infeção ascendente, ou outros fatores. Ou seja, poderia ter ocorrido infeção antes do trabalho de parto, ainda in-utero, concorrendo par a interpretação de alguns autores. ${ }^{(13)}$ Também a realização repetida de exame vaginal para avaliação de cervicometria aumenta a possibilidade de corioamniotite. $\mathrm{O}$ procedimento não raras vezes é frequente até à decisão para cesareana. De facto, se há rotura de membranas, o risco relativo de infeção por realização de três ou mais toques vaginais cresce entre 2 a 5 vezes. ${ }^{(12)}$

Amamentação interrompida (i.e., 00105): na fase pos-parto imediato, os diagnósticos relacionados com dificuldades na amamentação são frequentes. ${ }^{(3)} \mathrm{Na}$ participante, a situação está agravada, pois em ocorrência de cesariana, existe menor habilidade materna para amamentar nas primeiras tentativas. (14) Tal pode ter sido o motivo inicial para a baixa produção de colostro. Por outro lado, o bebé-Ana fez alimentação mista (i.e., formula, leite materno por amamentação, leite materno extraído com bomba), método que diminui a produção de ocitocina e prolactina, por menor estimulação. É ainda de considerar que neste método diminui, a retirada do fator inibidor da lactação (FIL) produzido em mecanismo autócrino. Eventualmente, a extração de leite com bomba, pode agir como via de infeção. Há relatos de sepsis neonatal por contaminação das mãos ou dos equipamentos de extração de leite ${ }^{(15)}$ ou carência de higiene corporal da mãe. ${ }^{(16)}$ Há ainda autores que reconhecem a possibilidade de EOS higiene precária das mãos de quem manipula o RN. ${ }^{(13,15)}$ 
Disposição para tomada de decisão melhorada (i.e., 00184): o nascimento de um filho transporta em geral modificaçóes no espaço que a família ocupa, assim como nos processos interrelacionais. ${ }^{(3)} \mathrm{No}$ caso atual é constatado, a relação que o estatuto sociocultural das mulheres pode ter, face à precaridade da saúde e ao papeis femininos na família tal como é apontado por alguns autores. ${ }^{(2,3)}$ Viver sem saneamento básico transporta riscos elevados na saúde, nomeadamente no período neonatal. Tal é reconhecido em estudo comparativo, que regista maior percentual de sepsis em crianças de etnia cigana na unidade de Neonatologia. ${ }^{(17)} \mathrm{e}$ também em estudos que registam precaridade de cuidados $^{(18)}$. O facto da mãe-Ana querer saber mais sobre a situação do seu filho, assim como ter reconhecido a necessidade de vigilância no Programa de Saúde Infantil, são promissoras de melhor saúde e revelam a importância de considerar a díade como unidade de cuidados ${ }^{(18)}$. Contudo dado o estatuto da mulher cigana na família, será necessário fortalecer esta disposição para decisão melhorada. Maria será uma mãe a referenciar para apoio social, sem, contudo, desrespeitar a hierarquia do clã. Algumas autarquias dispóem de figuras da mesma etnia, que atuando como mediadores, facilitam o acesso aos cuidados de saúde e a integração social. É necessário ter em conta que na família cigana, a mulher jovem, está limitada nas tomadas de decisão, que são concertadas de acordo com o parecer do líder e a matriarca da família (i.e., decisão de usar os serviços de saúde para vigilância pré-natal).

Em síntese: A situação clínica do bebé-Ana melhorou, tendo alta 10 dias depois. Todos os diagnósticos levantados para o bebé-Ana foram encerrados ao $9^{\circ}$ dia de internamento. Os diagnósticos levantados para a Maria, foram encerrados no dia da saída, já que dado o seu contexto socioétnico, houve necessidade de apoio dos serviços sociais. $\mathrm{O}$ caso de sepsis seria evitável se Maria conhecesse a assistência portuguesa gratuita no ciclo gravídico-puerperal (i.e., decreto-lei no 70/2000 de 4 de maio) e se existisse maior aproximação entre o clá versus os serviços de saúde. Além do prejuízo dos 10 dias de internamento hospitalar, na vida da díade e restante família, nas suas finanças e noutros não contabilizáveis, existiu agravo para os contribuin- tes. De facto, a diária de internamento hospitalar de $\mathrm{RN}$ com peso ao nascer $>2499 \mathrm{~g}$, por infeçóes congénitas/perinatais, varia de acordo com a severidade do caso, entre 432,25€ e 1223.19€/dia (i.e., Portaria no2017/2017 de 11 julho), o que significa no caso do bebé-Ana uma estimativa de $4320.35 €$ a $12230.19 €$. Na realidade algo diferente da soma de 6 a 8 episódios de visita pré-natal realizada por enfermeiro(a) ao acampamento (i.e., cada episódio domiciliário 33.10€; Portaria 20/2014 de 29 janeiro) acrescido da deslocação de viatura (i.e., DecretoLei n. ${ }^{\circ}$ 137/2010, de 28 de dezembro). Porventura, através de programas domiciliários ou agendando a regularidade de presença na instituição de saúde, pode potencializar-se a saúde de minorias étnicas, com custos menos elevados e mais ganhos em saúde.

Os procedimentos metodológicos na abordagem aos participantes são uma limitação, já que não se obteve consentimento informado na forma escrita, por impossibilidade dos participantes. Tal é uma fragilidade ética do estudo. Contudo esta fragilidade mostra, na evidência da clínica, a necessidade de dar voz às minorias éticas, que por carências educacionais, culturais ou económicas necessitam mais atenção. Em respeito pela dignidade das pessoas, qualquer que seja a idade, género ou condição social, o papel dos enfermeiros, reside também no advogar em favor dos mais desprotegidos.

\section{Conclusão}

O RN apresentava sintomatologia pouco concreta, o que é típico da EOS. Concretizou-se o quadro clínico de sepsis, através de sinais e sintomas, de analises clínicas e interpretando a história obstétrica da mãe. A EOS pode ser prevenida, diminuindo a morbimortalidade. Os diagnósticos NANDA-I reportando-se à díade, concretizam na criança, problemas e riscos atuais, além de riscos futuros para o desenvolvimento. No caso da mãe, os diagnósticos NANDA-I apontam essencialmente para os obstáculos radicados no género e na cultura. Sugere o caso, que a marcada hierarquia familiar, ao ter influencia sobre os aspetos da vida privada da (i.e., afetivos e reprodutivos), retira a capacidade de decisão da mu- 
lher e conduz a menor acesso aos cuidados de saúde. A saúde das minorias étnicas em fase procriativa pode ser potencializada. A vigilância pré-natal, conforme o programa gratuito do Serviço Nacional de Saúde em Portugal, poderia ter oferecido à mãe os recursos e ensinamentos para a prevenção da EOS. É importante que às mulheres em idade reprodutiva chegue a informação sobre cuidados de saúde. No caso dos ciganos, a situação póe-se com particular acuidade, pois o casamento ocorre em idade adolescente, é definido pelas figuras da geração anterior e a maternidade precoce é elevada. Na região, os clâs circulam frequentemente e é necessário criar condiçôes para que tenham mais saúde, já que são socialmente frágeis e tanto os próprios criam os seus redutos, como a população os ostraciza. Será assim de interesse desenvolver programas de cuidado culturalmente congruente, com particular atenção às mães-meninas, que precocemente se tornam meninas-mães. Saliente-se ainda a precária condição feminina nestes grupos. Considerando os aspetos metodológicos de abordagem ao caso, é necessário reconhecer que a taxonomia NANDA-I não é utilizada no sistema de saúde em Portugal. Porém é necessário divulgar e exercita-la nas instituiçóes de ensino de enfermagem e nos campos clínicos onde há estudantes. De facto, não só os estudantes portugueses são futuros profissionais a para o mundo, como vários estudantes estrangeiros realizam mobilidade nas universidades portuguesas. Os estudos de caso, sendo a primeira evidência com que os estudantes se deparam, são ótimos meios para exercitar as taxonomias de enfermagem.

\section{Colaborações}

Urbanovská N, Pedro C e Sim-Sim MMSF contribuíram com a concepção do projeto, análise e interpretação dos dados, redação artigo, revisão crítica relevante do conteúdo intelectual e aprovação da versão final a ser publicada.

\section{Referências}

1. Shane AL, Stoll BJ. Neonatal sepsis: progress towards improved outcomes. J Infect. 2014;68 Suppl 1:S24-32.

2. Cortese F, Scicchitano P, Gesualdo M, Filaninno A, De Giorgi E, Schettini $F$, et al. Early and late infections in newborns: where do we stand? A review. Pediatr Neonatol. 2016;57(4):265-73.

3. Vieira F, Bachion M, Salge A, Munari D. Diagnósticos de enfermagem da NANDA no período pós-parto imediato e tardio. Esc Anna Nery. 2010;14(1):83-9.

4. Oza S, Lawn JE, Hogan DR, Mathers C, Cousens SN. Neonatal causeof-death estimates for the early and late neonatal periods for 194 countries: 2000-2013. Bull World Health Organ. 2015;93(1):19-28.

5. Santos AP, Silva ML, Souza NL, Mota GM, França DF. Nursing diagnoses of newborns with sepsis in a neonatal intensive care unit. Rev Lat Am Enfermagem. 2014;22(2):255-61.

6. Barros AL. Classificações de diagnóstico e intervenção de enfermagem: NANDA-NIC. Acta Paul Enferm. 2009;22(Espec):864-7.

7. Galdeano LE, Rossi LA, Zago MM. Roteiro instrucional para a elaboração de um estudo de caso clínico. Rev Lat Am Enfermagem. 2003;11(3):371-5.

8. Herdman T. Diagnósticos de Enfermagem da NANDA Internacional. In: Herdman T, Kamitsuru S, editors. Diagnósticos de Enfermagem da NANDA Definições e classificação 2015-2017. Porto Alegre: Artmed; 2015. p. 127-442.

9. Bonito R. Manual de neonatologia. Mexico: McGraw Hill; 2012. 653 p.

10. Ricci S. Enfermagem materno-neonatal e saúde da mulher. Rio de Janeiro: Guanabara Koogan; 2015. 350 p.

11. Matsuno AK. Insuficiência respiratória aguda na criança. Medicina (Ribeirao Preto). 2012;45(2):168-84.

12. Tita AT, Andrews WW. Diagnosis and management of clinical chorioamnionitis. Clin Perinatol. 2010;37(2):339-54.

13. Simonsen KA, Anderson-Berry AL, Delair SF, Davies HD. Early-onset neonatal sepsis. Clin Microbiol Rev. 2014;27(1):21-47.

14. Hobbs AJ, Mannion CA, McDonald SW, Brockway M, Tough SC. The impact of caesarean section on breastfeeding initiation, duration and difficulties in the first four months postpartum. BMC Pregnancy Childbirth. 2016;16:90.

15. Smith SL, Serke L. Case report of sepsis in neonates fed expressed mother's milk. J Obstet Gynecol Neonatal Nurs. 2016;45(5):699-705.

16. Le Doare K, Kampmann B. Breast milk and Group B streptococcal infection: Vector of transmission or vehicle for protection? Vaccine. 2014;32(26):3128-32.

17. Sastre Gussoni E, Miranda León MT, Muñoz Hoyos A, Galdó Muñoz G. [Health status of gypsy and non-gypsy children in a health district in Granada]. An Esp Pediatr. 2000;53(3):223-8. Spanish.

18. Adatara P, Afaya A, Salia SM, Afaya RA, Konlan KD, AgyabengFandoh $E$, et al. Risk factors associated with neonatal sepsis: a case study at a specialist hospital in Ghana. ScientificWorldJournal. 2019;2019:9369051. 